\title{
Hyper Prevalence of Malnutrition in Nigerian Context
}

\author{
Aruaye Afeye Obada ${ }^{1}$, Aondover Eric Msughter ${ }^{2 *}$, Hadiza Mustapha Namadi ${ }^{3}$ and Tsendiir \\ Nongubee ${ }^{4}$
}

${ }^{1}$ Aruaye Afeye Obada, Department of Microbiology, University of Calabar, Nigeria

${ }^{2}$ Aondover Eric Msughter, a lecturer in the Department of Mass Communication, Skyline University Nigeria

${ }^{3}$ Hadiza Mustapha Namadi, Department of Mass Communication, Bayero University, Kano, Nigeria

${ }^{4}$ Tsendiir Nongubee, Department of Mass Communication, Bayero University, Kano, Nigeria

*Corresponding author: Aondover Eric Msughter, Aondover Eric Msughter, a lecturer in the Department of Mass Communication,

Skyline University Nigeria

\section{ARTICLE INFO}

Received: 幽 September 13, 2021

Published: 慧 September 24, 2021

Citation: Aruaye Afeye Obada, Aondover Eric Msughter, Hadiza Mustapha Namadi, Tsendiir Nongubee. Hyper Prevalence of Malnutrition in Nigerian Context. Biomed J Sci \& Tech Res 39(1)-2021. BJSTR. MS.ID.006236.

Abbreviations: HANS: Health and Nutrition Survey; WHO: World Health Organization; UK: United Kingdom; WFP: World Food Programme; NCDs: Non-Communicable Diseases; NFCNS: Nigerian Food Consumption and Nutrition Survey; MICS: Multiple Indicator Cluster Survey; PEM: Protein Energy Malnutrition; SSA: Sub Saharan Africa; SDGs: Sustainable Development Goals; TRA: Theory of Reasoned Action; TBP: Theory of Planned Behaviour; IQ: Intelligent Quotient

\author{
ABSTRACT
}

Diet is currently the number one risk factor for disease in the world; carrying a superior risk of sickness than smoking or drinking alcohol. According to the World Health Organization, 462 million adults are underweight, while 1.9 billion adults are overweight and obese. In children under 5 years of age, 155 million are stunted, 52 million are wasted, 17 million are severely wasted and 41 million are obese. Globally, there is hunger and malnutrition ravaging the world with a current estimated value of 1 in 9 people out of the 820 million people who are hungry or malnourished. Thus, the study found that Nigeria is one of the African countries listed among the 20 countries responsible for $80 \%$ of global malnutrition. The finding of the study also revealed that over the years, two main types of malnutrition have been identified in Nigerian children: protein-energy malnutrition and micronutrient malnutrition. The study discovered that the causes of malnutrition and food insecurity in Nigeria are multidimensional and include very poor infant and young child breastfeeding or feeding practices, which contribute to high rates of illness and poor nutrition among children under 2 years. The study discovered that young children with protein energy malnutrition suffer from brain atrophy; a shrinking of brain cells due to a lack of nutrients. The findings of the study revealed that stunted children earn as much as $20 \%$ less than their counterparts, and that today's malnutrition could potentially cost the global economy $\$ 125$ billion. The study concludes that nutrition is not only significant for increasing economic outcomes of individuals; it is important for nations' economic development, especially for a developing country like Nigeria. Based on the findings, the study recommends that the National Health and Nutrition Survey (HANS), and the Federal Ministry of Health should liaise to produce foods that are rich in nutritive contents.

Keywords: Malnutrition; Obesity; Overweight; Stunted Growth; Under Nutrition and Underweight

\section{Introduction}

Diet is the number one risk factor for disease in the world; carrying a superior risk of ill health than smoking or drinking alcohol Mills, et al. [1]. According to the World Health Organization (WHO), 462 million adults are underweight, while 1.9 billion adults are overweight and obese. In children under 5 years of age, 155 million are stunted, 52 million are wasted, 17 million are severely wasted and 41 million are overweight or obese [2]. The importance of nutrition cannot be over emphasized in any country of the world, be it developed, developing or under developed. This is because nutrition determines the social, economic, intellectual and technological advancement of any nation. While the significance 
of nutrition for growth, development and advancement is globally recognized, universal efforts in battling hunger and malnutrition have not really been achieved on a global scale [3,4]. Globally, there is hunger and malnutrition ravaging the world with a current estimated value of 1 in 9 people out of the 820 million people who are hungry or undernourished. A study conducted by [4] states that there has been a perpetual increase in these figures since 2015, especially in Africa, West Asia and Latin America. Similarly, approximately 113 million people across 53 countries experience acute hunger, as a result of conflict and food insecurity, climate shocks and economic instability [5]. However, more than onethird of the world's adult population is overweight or obese, with growing trends over the past twenty years $\mathrm{Ng}$, et al. [6].

The 2020 Global Nutrition Report presents the latest data and evidence on the state of global nutrition. Among children under 5 years of age, 149.0 million are stunted, 49.5 million are wasted and 40.1 million are overweight, and there are 677.6 million obese adults. It further states that there is now an increased global recognition that poor diet and resultant malnutrition are among the greatest health and societal challenges of our time. In addition, malnutrition continues at unacceptably high levels on a universal scale despite the little improvements that has been made to combat it. [7] emphasises that countries affected by conflict or other forms of fragility are at a higher risk for malnutrition. Moreover, it further illustrates that in 2016, 1.8 billion people (24\% of the world's population) were living in fragile or extremely delicate countries. This digit is projected to grow to 2.3 billion people by 2030 and 3.3 billion by 2050. International Food Policy Research Institute, [8] notes that the prevalence of stunting or restricted growth among children under five years reduced to $23.8 \%$ from $36.9 \%$ between 1990 and 2015. Nonetheless, the Food and Agricultural Organization of the United Nations [9] indicated that in 2017, the number of undernourished people increased from 777 million to 815 million between 2015 and in 2016, about 155 million children below the age of 5 were too short for their age. Furthermore, approximately 52 million did not weigh enough for their height while about 41 million was overweight. Previous researches like Black, et al. $[8,10]$, and [11] indicated that malnutrition is connected to nearly half of all deaths among children under the age of five.

On the contrary, more than 28 million adults and children in the United Kingdom (UK) are overweight or obese, which is catalysing a diet related health problem with escalating rates of noncommunicable diseases, including type 2 diabetes, cardiovascular disease and certain forms of cancer [12]. The treatment of obesity and its consequences in England alone currently costs the NHS $£ 16$ billion every year, the majority of which is spent on type 2 diabetes, [13]. This is more than the $£ 13.6$ billion per year spent on the fire and police services combined. The wider economic toll of obesity and related conditions is estimated to be the equivalent of 3\% of the GDP Dobbs, et al. [14]. The most common form of malnutrition in the developing countries is under nutrition whilepresently Nigeria is one of the African countries listed among the 20 countries responsible for $80 \%$ of global malnutrition. Out of the sum of 233 million undernourished people in Africa, 220 million are from the Sub Saharan. Whereas South Sudan is lacking of globally comparable data, estimates show that the food and nutritional shortfalls are dreadful. For example, by January-March 2019, 5.2 million South Sudanese (49\% of the total population) continued to face acute food insecurity Black, et al. [15]. Within this context, this paper seeks to evaluate hyper prevalence of malnutrition in Nigerian context.

The Basic Tools of Scientific Enquiry

1. What are the factors or causes of hyper prevalence of malnutrition in Nigeria?

2. What are the mental and intellectual effects of hyper prevalence of malnutrition in Nigeria of under five children?

3. What are the impacts of hyper prevalence of malnutrition on the future of the Nigeria economy?

\section{Literature Review}

A report by the Food and Agriculture Organization of the United Nations [16] indicates that more than $14 \%$ of the population in developing countries were undernourished in the period between 2011 and 2013. Malnutrition includes both nutrient deficiencies and excesses and is defined by the World Food Programme (WFP) as "a state in which the physical function of an individual is diminished or weakened to the point where the person can no longer maintain normal or adequate bodily performance processes such as growth, pregnancy, lactation, physical work, and resistance to and recovering from disease" [17]. Additionally, [18] states that malnutrition frequently begins at conception, and child malnutrition is connected to poverty, low levels of education, and poor access to health services, including reproductive health and family planning. Furthermore, the World Health Organization, [2] states that malnutrition occurs due to an imbalance in the body, whereby the nutrients required by the body and the amount used by the body do not balance. Additionally, it stipulated that there are several forms of malnutrition and these include two broad categories namely under nutrition and over nutrition. Under nutrition manifests as wasting or low weight for height (acute malnutrition), stunting or low height for age (chronic malnutrition), underweight or low weight for age, and mineral and vitamin deficiencies or excessiveness. While over nutrition includes overweight, obesity and dietrelated non-communicable diseases (NCDs) such as diabetes mellitus, heart disease, some forms of cancer and stroke.

In the $21^{\text {st }}$ century, malnutrition in children has three main strands. The first is the continuing plague of undernutrition. 
Despite its reduction in many parts of the world, undernutrition is still depriving many children of the energy and nutrients they need to grow well and is connected to the deaths of children from 6 months to under 5 of age each year [19]. The second strand is hidden hunger. This is as a result of the deficiencies in essential vitamins and minerals such as vitamins $A$ and $B$, iron and zinc. It is often unseen, and often ignored; hidden hunger robs children of their health and vitality and even their lives. The third strand is overweight, which is also called obesity in its more severe form. It was formally regarded as a condition of the rich, overweight now afflicts more and more children, even in underdeveloped and developing countries. It is has also been considered as a threat to stimulating a rise in diet-related noncommunicable diseases (NCDs) later in life; such as heart disease, which is the leading cause of death worldwide [20]. World Health Organization (WHO) reported that 462 million adults are underweight, while 1.9 billion adults are overweight or obese. In children under 5 years of age, 155 million are stunted, 52 million are wasted, 17 million are severely wasted and 41 million are overweight or obese [2]. There is a diversemanifestation of malnutrition, but the pathways to addressing prevention are important and include exclusive breastfeeding for the first two years of life, diverse and nutritious foods during childhood, healthy environments, access to basic services such as water, hygiene, health and sanitation, as well as pregnant and lactating women having proper maternal nutrition before, during and after the respective phases (before pregnancy and after delivery) [21].

The smallest or least advantaged are the most likely to suffer from malnutrition and its longstanding consequences. A research report by Hancock, et al. [22] states that the most deprived white children measured across England in 2012-2013 were on average more than a centimetre shorter in height by the age of 10 years than the least deprived children. These children are not likely to catch up growth losses from their early years. Obese children in England are more than twice as likely to live in the most deprived areas compared with comfortable areas and this gap is increasing over time [23]. Poor children are also more likely than wealthy children to suffer from poor health as a result of food insecurity. In addition, over $60 \%$ of paediatricians surveyed throughout the UK in late 2016 said that food insecurity contributed to the unpleasant health among children they treat [24]. Currently, nearly one in three people in the world suffers from at least one form of malnutrition, including obesity, under nutrition or vitamin and mineral deficiencies. Due to the rise in obesity, high income countries are presently contributing to the greatest number of malnourished people, but low income and middle income countries are meeting up fast. Hence, in Africa, the number of children who are overweight or obese has nearly doubled from 5.4 million in 1990 to 10.6 million in 2014 (Global Panel on Agriculture and Food Systems for Nutrition, 2016). Despite this rise in figure, other forms of malnutrition have not gone away, as deficiencies in vitamins and minerals continue to affect billions of people worldwide.

\section{Perspectives on Malnutrition in Nigeria}

Over the years, two main types of malnutrition have been identified in Nigerian children: (1) protein-energy malnutrition and (2) micronutrient malnutrition. The protein-energy malnutrition is common among the preschool children and constitutes a major public health problem in the country. "Stunting" is usually defined as low height for age, however, it is a deficit of linear growth and failure to reach genetic potential that reflects long term and cumulative effects of inadequate dietary intake and poor health conditions [25]. Succinctly, underweight is low weight for age, stunting (low height for age) and wasting (low weight for height) are all manifestations of under nutrition. All these expose the child to health risks and in their severe forms; they constitute a threat to the child's survival [26]. In 1983-1984, the National Health and Nutrition Survey (HANS) conducted by the Federal Ministry of Health estimated the prevalence of wasting to be around 20\% (FGN 1983-1984). A research by the Demographic and Health Survey (DHS) in 1986 shows that children between the ages of 6-36 months in Ondo State (Southwestern Nigeria) suffered 6.8\% prevalence of wasting, underweight of $28.1 \%$, and stunting of $32.4 \%$.

In February 1990, an anthropometric survey of preschool children (2-5 years old) in seven states was conducted and found underweight prevalence ranging from 15\% in Akure (Ondo State) to $52 \%$ in Kaduna (Kaduna State) while stunting prevalence ranged from $14 \%$ in Iyero-Ekiti (Ondo State) to $46 \%$ in Kaduna. Similarly, the 1990 DHS conducted by the Federal Office of Statistics estimated the prevalence of wasting at $9 \%$, underweight at $36 \%$, and stunting at $43 \%$ among the preschool children in Nigeria. These figures show a decline compared to the figures published in 1994 by UNICEF-Nigeria from a 1992 survey conducted among women and children in 10 states; the UNICEF reported the prevalence of wasting among women and children at $10.1 \%$, underweight $28.3 \%$, and stunting $52.3 \%$. Furthermore, there was a decrease in prevalence of stunting in the 2003 NDHS with $11 \%$ of children wasting, $24 \%$ underweight, and $42 \%$ of children stunted [27]. As at 2008 , prevalence of underweight had declined to $23 \%$ and stunting had reduced to $41 \%$ but wasting increased to $14 \%$ (NDHS, 2008).

Similar trends were reported by the 2001-2003 Nigerian Food Consumption and Nutrition Survey (NFCNS). The study reported $9 \%$ wasting, $25 \%$ underweight, and $42 \%$ stunting, with significant variations across rural and urban areas, geopolitical zones, and agro-ecological zones Maziya-Dixon, et al. [28]. The study also shows that the prevalence of stunting was lowest in the southeast at $16 \%$; it reached $18 \%$ in the south and $55 \%$ in the northwest of Nigeria. The result further shows that among the states, stunting 
was highest among children in Kebbi (61\%). The 2003 report of NDHS also indicates that among the rural children (43\% stunted) were disadvantaged compared to urban children (29\% stunted). Children living in the Northwest geopolitical zone stood out as being particularly underprivileged at 55\% compared to $43 \%$ in the Northeast zone, 31\% in North Central, 25\% in the Southwest, $21 \%$ in the South-South, and $20 \%$ in the Southeast. The Multiple Indicator Cluster Survey (MICS), reported that there was a decrease in the prevalence of malnutrition in Nigeria with $34 \%$ of children under five stunted, $31 \%$ underweight, and $16 \%$ wasted, while about $15 \%$ of children had low birth (at less than 2,500 grams at birth) [29]. It is obvious from the 2013 NDHS that the proportion of children who are stunted has been decreasing over the years. However, the degree of wasting has worsened, indicating a more recent nutritional deficiency among children in the country. Prevalence of stunting decreased to $37 \%$, with a higher concentration among rural children $(43 \%)$ than urban $(26 \%)$. Nevertheless, there has been an increase in the proportion of children underweight (29 $\%)$ and the proportion wasting (18\%) [30]. It is graphically clear based on the data from these different studies that, malnutrition of children under five has been a consistent problem in Nigeria over time, with just little improvement reported despite its escalation in the country. Malnutrition contributed to $53 \%$ of deaths among children under five in Nigeria, and levels of wasting and stunting are still very high [31].

\section{Empirical Review}

Malnutrition is a global public health problem in both children and adults universally [2]. Annually, malnutrition claims the lives of 3 million children under age five and costs the global economy billions of dollars in lost productivity and health care costs. However those losses are almost entirely preventable. A large body of scientific evidence like [32-34] show that improving nutrition during the critical 1,000 day period from a woman's pregnancy to her child's second birthday has the potential to save lives, help millions of children to fully develop and deliver greater economic prosperity. Furthermore, Shrimpton, et al. [35] stated that malnutrition is currently an important global problem; as it affects all people despite the geography, socioeconomic status, sex and gender, overlapping households, communities and countries. In addition, anyone can experience malnutrition but the most susceptible groups affected are children, adolescents, women, as well as people who are immunecompromised, or facing the challenges of poverty.

Young malnourished children are affected by compromised immune systems by yielding to infectious diseases and are prone to cognitive development delays; damaging long term psychological and intellectual development effects, as well as mental and physical development that are compromised due to stunting $[10,36]$. A malnutrition cycle exists in populations experiencing chronic under nutrition and in this cycle, the nutritional requirements are not met in pregnant women. Thus, infants born to these mothers are of low birth weight, are unable to reach their full growth potential and may therefore be stunted, susceptible to infections, illness, and mortality early in life. The cycle is worsened when low birth weight females grow into malnourished children and adults, and are therefore more likely to give birth to infants of low birth weight as well [37]. Malnutrition is not just a health issue but also affects the global burden of malnutrition socially, economically, developmentally and medically, affecting individuals, their families and communities with serious and long lasting consequences [2].

It is very significant that malnutrition is addressed in children as it manifestations and symptoms begin to appear in the first 2 years of life [35]. Overlapping with the mental development and growth periods in children, protein energy malnutrition (PEM) is said to be a problem at the ages of 6 months to 2 years. Therefore, this age and period is considered a window period during which it is essential to prevent or manage acute and chronic malnutrition [38]. Furthermore, children less than 5 years of age have a disease burden of 35\% Black, et al. [10]. In 2008, 8.8 million global deaths in children less than 5 years old were due to underweight, of which 93\% occurred in Africa and Asia. Walton, et al. [39] stated that approximately one in every seven children faces mortality before their fifth birthday in Sub Saharan Africa (SSA) due to malnutrition. Nigeria is the most populous nation in Africa and has a population of almost 186 million people in 2016 UNICEF [40]. With a high fertility rate of 5.38 children per woman, the population is growing at an annual rate of 2.6 percent, escalating and worsening overcrowded conditions. Hence, by 2050, Nigeria's population is expected to grow to an astounding 440 million, which will make it the third most populous country in the world, after India and China (Population Reference Bureau, 2013). A report by the Nigeria Federal Ministry of Health [41] states that scarcity of resources and land in rural areas has resulted in Nigeria having one of the highest urban growth rates in the world at 4.1 percent. Furthermore, out of the 157 countries in progress toward meeting the Sustainable Development Goals (SDGs), Nigeria ranks 145th Sachs, et al. [42].

Malnutrition in childhood and pregnancy has many adverse consequences for child survival and longstanding wellbeing. It also has extensive consequences for human capital, economic productivity, and national development generally. These consequences of malnutrition should be a significant concern for policy makers in Nigeria, which has the highest number of children under 5 years with chronic malnutrition (stunting or low height for age) in SubSaharan Africa at more than 11.7 million, according to the Demographic and Health Survey National Population Commission and ICF International [43]. According to the World Bank [44], Nigeria's economy is the largest in Africa and is well- 
positioned to play a leading role in the global economy. However, despite the strong economic growth over the last decade, poverty has remained significantly high, with increasing inequality and provincial disparities. In addition, it is estimated that 69 percent of Nigerians live below the relative poverty line (US\$1.25 per day), compared to the 27 percent in 1980.

\section{Theoretical Framework}

This study is anchored on two theories, which include the Theory of Reasoned Action (TRA) and the Theory of Planned Behaviour (TBP). Theory of Reasoned Action was formulated by Martin Fishbein and IcekAjzen towards the end of the 1960s. On the other hand, IcerkAjzen proposed the Theory of Planned Behaviour in 1985; which was an extension from the TRA. The Theory of Reasoned Action and Theory of Behaviour Planned combine two sets of belief variables, which are 'behavioural attitudes' and 'the subjective norms'. The behavioural attitudes are defined as the multiplicative sum of the individual's relevant likelihood and evaluation related to behavioural beliefs. On the other hand, subjective norms are referent beliefs about what behaviours others expect and the degree to which the individual wants to comply with others' expectations. The summary of the two theories suggest that a person's health behavior is determined by their intention to perform a behavior (behavioural intention) it also is predicated by a person's attitude toward the behavior, and the subjective norms regarding the behavior.

The Theory of Reasoned Action has been criticised because it is said to ignore the social nature of human action Kippax, et al. [45]. These behavioral and normative beliefs are derived from individuals perceptions of the social world they inhabit, and are hence likely to reflect the ways in which economic or other external factors shape behavioral choices or decisions. In addition, there is a compelling logical case to the effect that the model is inherently biased towards individualistic, rationalistic, interpretations of human behavior. Its focus on subjective perception does not essentially permit it to take meaningful account of social realities. However individuals' beliefs about such issues are unlikely going to reflect the accurate potential and observable social facts. As such, the Theory of Planned Behavior updated the Theory of Reasoned Action to include a component of perceived behavioral control, which brings about one's perceived ability to enact the target behavior. Actually, perceived behavioral control was added to the model to extend its applicability beyond purely volitional behaviors. Previous to this addition, the model was relatively unsuccessful at predicting behaviors that were not mainly under volitional control. Therefore, the Theory of Planned Behavior proposed that the primary determinants of behavior are an individual's behavioral intention and perceived behavioral control.
A constructive use of the TRA and TBP in research and public health intervention programmes might well contribute valuably to understanding issues related to health inequalities and the roles that other environmental factors have in determining health behaviors and outcomes. In spite of the criticism, the general theoretical framework of the TRA and TPB has been widely used in the retrospective analysis of health behaviors and to a lesser extent in predictive investigations and the design of health interventions Hardeman, et al. [46]. This is why there is a connection between the study and the theory; since it is health related within theoretical postulations.

\section{Methodology}

The study uses secondary data such as significant texts, journals, newspapers, official publications, historical documents and the Internet. However, the research was strictly limited to available or recorded information about malnutrition, its prevalence, effects and impacts on the Nigeria economy that can be found in scholarly journals, books and the internet. The study adopts content analysis as its method of analysis, whereby the existing literature will be considered for the analysis.

\section{Findings and Discussion}

Based on the stated research questions, the findings and discussions are purely based on the research questions. The questions are discussed as follows:

\section{RQ1: What are the Factors or Causes of Hyper Prevalence of Malnutrition in Nigeria?}

The causes of malnutrition and food insecurity in Nigeria are multidimensional and include very poor infant and young child breastfeeding or feeding practices, which contribute to high rates of illness and poor nutrition among children under 2 years; lack of access to healthcare, water, and sanitation; armed conflict, mainly in the north; irregular rainfall and climate change; hyper unemployment level; and poverty Nigeria Federal Ministry of Health, Family Health Department [41]. While chronic and seasonal food insecurity occurs throughout the country, and is worsened by volatile and rising food prices, the impact of conflict and other shocks has resulted in acute levels of food insecurity in the North East zone FEWSNET [47]. Furthermore, an approximated 3.1 million people in the states of Borno, Yobe, and Adamawa received emergency food assistance and cash transfers in the first half of 2017 but, the numbers who need assistance is likely far bigger because much of the North East zone has been inaccessible to humanitarian or aid agencies FEWSNET [47].

World Bank [44] stated that the current administration, led by President Muhammadu Buhari, identifies fighting corruption, 
increasing security, tackling unemployment, diversifying the economy, enhancing climate resilience, and boosting the living standards of Nigerians as its core policy priorities. On the contrary, the country is seriously facing a major challenge of threat in the northeast because of the militant Islamic group, Boko Haram, which is destroying infrastructure and conducting assassinations and abductions. As of August 2017, conflict in northeastern Nigeria had displaced more than 1.7 million people within the country and forced nearly 205,000 people to flee into neighboring Cameroon, Chad, and Niger Republic, making it difficult to access food resources in the regions. In addition, violence has interrupted agricultural and income generating activities, reducing household purchasing power and access to food. Furthermore, populations in the regions of northeastern Nigeria are inaccessible to humanitarian assistance and markets are in terrible conditions USAID [48]. Hence, diet related non communicable diseases are also on the increase in Nigeria due to globalization, urbanization, lifestyle transition, socio cultural factors, and poor maternal, fetal, and infant nutrition Nigeria Federal Ministry of Health, Family Health Department [41].

Other factors include, those related to women's empowerment, such as mothers' working status, control over resources and educational attainment. In rural areas, children of working mothers are significantly less possible to be undernourished than children living in households where mothers do not work (Ajieroh, 2009). Hence, in Nigeria, children from the poorest households are almost 3 times more likely to be stunted and almost 4.3 times more likely to be severely stunted compared to children from the richest households. Similarly, according to NPC and ICF International (2014) the findings of a study of factors affecting Nigerian children's nutritional status suggest that households' economic status is significantly associated with their nutritional status. This is because the very poor and the poor constitute $74 \%$ of the population and cannot afford a nutritious diet.

Furthermore, the analyses of regional differences in child malnutrition reveal important spatial inequalities. The prevalence of underweight, stunting and wasting is generally higher in the northern than the southern states. The highest proportions of malnourished children were found mainly in Bauchi, Jigawa, Kaduna, Katsina, Kebbi, Sokoto and Zamfara states. In all these states the occurrence of stunting exceeds 50\%. In other states, such as Gombe, Taraba, Yobe and Kano, the prevalence of stunting exceeds $40 \%$. All the states in the North West (except Jigawa and Zamfara) show higher figure than the national average prevalence of acute malnutrition (wasting). In addition, the North-Eastern states of Bauchi, Borno and Yobe have excessively high burden of wasting, with Kano State showing more than twice the national average (39.7\%). Severe acute malnutritionis highest in Kaduna (27.6\%) and Kano (25.1\%) and lowest in Bayelsa (1.3\%).
Consequently, the UN Office for the Coordination of Humanitarian Affairs (2014) stated that Nigeria has the second highest acute malnutrition burden in the world, with an estimated 3.78 million children suffering from wasting.

\section{RQ2: What are the Mental and Intellectual Effects of Hyper Prevalence of Malnutrition in Nigeria of Under Five Children?}

The growth of the brain, including neurodevelopment begins in the womb within one week of conception. During this period of rapid growth, protein and energy (from carbohydrates and fat sources) are extremely important. A lack of these nutrients can have very damaging effects. Fuglestad, et al. [49] showed a higher occurrence of brain abnormalities at two years of age among children affected by foetal under nutrition. Furthermore, studies of young children with protein energy malnutrition alsoindicated brain atrophy; a shrinking of brain cells due to a lack of nutrients Blaack, et al. [10]. In addition, inadequate calories have continue to affect children's brain growth and enlargement immediately in the first months after birth, which was supposed to be a time of fast neurodevelopment, including the establishment of the parts of the brain fundamental for memory (the hippocampal-prefrontal connections Fuglestad, et al. [49].

The deficiency of iron also complicates the growth period of a child. Iron deficiency before two to three years of age may results in intense and possibly permanent myelin (fatty lipids and lipoproteins, which surround the axon of a nerve) changes Fuglestad, et al. [48]. Iron also facilitates the production of neurotransmitters - the chemicals that pass messages between neurons, and it is involved in the function of neuroreceptors, which receive the neurotransmitters' messages Jukes, et al. [50]. According to Allen [51], emergent evidence suggests that maternal iron deficiency in pregnancy reduces foetal iron stores, perhaps into the first year of life. This leads to greater risk of damages in future mental and physical development.

Furthermore, the deficiency of iron is a strong risk factor for both short and long terms cognitive, motor and socio emotional deterioration Prado \& Dewey [52]. Besides, longitudinal study like Grantham-McGregor, et al. [53] have indicated that children who are anaemic during infancy have poorer cognition, lower school achievement and are more likely to have behaviour problems in later childhood; an effect that could occur as a result of direct biological processes or as a consequence of the impact of anaemia on children's education experiences. Iron deficiency is pervasive. Virtually half of children in low and middleincome countries, that is $47 \%$ of under 5 are affected by anaemia, and half of these cases are due to iron deficiency World Health Organization [54]. According to the World Health Organization (WHO), 42\% of pregnant women (56 million) suffer from anaemia Goonewardene, et al. [55]. 
Iodine deficiency is known to be the world's single greatest cause of preventable mental retardation. In 2007, WHO estimated that nearly 2 billion people had deficient iodine intake, and one third of them are children of school age The Lancet [56]. Iodine is indispensable to the production of thyroid hormones, which are essential for the development of the central nervous system. Serious iodine deficiency before and during pregnancy can lead to underproduction of thyroid hormones in the mother and cretinism (a condition of severely stunted and mental growth due to birth deficiency of thyroid hormones) in the child Prado, et al. [51]. Cretinism is characterized by mental retardation, deaf mutism (a psychological disorder in which it is difficult for the individual to speak in certain situations), partial deafness, facial deformities and cruelly stunted growth. It can lead on average to a loss of 10-15 intelligent quotient (IQ) points Morgane, et al. [57]. In addition, Fuglestad, et al. [48] stated that mild iodine deficiency can decrease motor skills.

Zinc plays an important role in brain development and is known to be vital for efficiency of communication between neurons in the hippocampus, where learning and memory processes occur Duke University Medical Center [58]. It is also fundamental to other biological processes that affect brain development, including DNA and RNA synthesis and the metabolism of protein, carbohydrates and fat Prado, et al. [51]. Additionally, Hamadani, et al. [59] stated that although the results of studies on the impact of zinc supplementation on cognitive outcomes are inconsistent, there appears to be a relationship between zinc deficiency and children's cognitive and motor development, including among low birth weight children Folate is prerequisite during initial foetal development to prevent neural tube defects and make sure that the neural tube forms accurately to create the brain and spinal cord. Iron folate supplementation is also significant for pregnant and breastfeeding mothers to prevent iron deficiency anaemia Black, [10]. Vitamin B12 and folate works together to produce red blood cells. Black [10] further stated that the deficiencies in both could affect brain development in infants. Like iron, vitamin B12 is also essential to the myelination process. Neurological symptoms of vitamin B12 deficiency appear to affect the central nervous system and in severe cases cause brain atrophy.

\section{RQ3: What are the Impacts of Hyper Prevalence of Malnutrition on the Future of the Nigeria Economy?}

According to Save the Child [60] the benefits of good nutrition do not stop with better educational results. By improving cognitive abilities, health, physical strength and stature, good nutrition in the early years can lead to greater wages in adulthood and hence promote the economic development of an entire country. In addition, Save the Child [60] presented evidence that stunted children earn as much as $20 \%$ less than their counterparts, and uses this to estimate that today's malnutrition could potentially cost the global economy $\$ 125$ billion when children born now reach working age. Hence, the interrelation between improved nutrition and economic growth is of great importance for human and economic development. It is a two way relationship. On the one hand, inclusive economic growth can contribute towards reductions in the prevalence of malnutrition. On the other hand, declines in malnutrition can have a transformative effect on the economic ability of individuals and the whole societies. Thus, by means of its impact both on children's cognitive development and on their physical health and development, malnutrition can have momentous effects on an individual's economic wellbeing in future. The World Bank (2006) suggests that malnutrition results in $10 \%$ lower lifetime earnings, whilestudy like Save the Child [60], that modeled the impact of malnutrition in the first 2-5 years of life placed this figure at $20 \%$.

Lancet Series (2008) reviewed cohort studies from Brazil, Guatemala, India, the Philippines and South Africa that all monitored children into adulthood, and established that stunting is associated with reduced earnings in later life. Similarly, Victoria, et al. [61] stated that the same review discovered that less severe stunting in Brazil and Guatemala was associated with higher adult incomes among both men and women. Furthermore, models using proof from across these longitudinal studies, combined with evidence on the relationship between education and earnings taken from 51 countries, have estimated that children who are stunted at age five earn $22 \%$ less than their non stunted counterparts. In addition, data from the same study has been used to evaluate that individuals who were not stunted in early childhood were more likely, by 28 percentage points to work in higher paying skilled labour or white collar work and earned as much as $66 \%$ more as adults Hoddinott, et al. [62].

Part of the impact of malnutrition on earnings may be because of the influence on children's physical development. Study like Morganeet, et al. [56] has confirmed the correlation between adult height and wages.For example, a large cross sectional study in Brazil found that a $1 \%$ increase in adults' height was associated with a $2.4 \%$ increase in earnings. Francis and Iyare (2006) and Islam et al., (2006) stated that there is a flawless association between education levels, and individuals' subsequent earnings. Very importantly, the latest evidence suggests that it is actual learning and the acquisition of skills that matter most, not just the number of years spent in school Hanushek, et al. [63]. This is another reason why early childhood development, boosted by good nutrition, is very vital. Hence, children need to start school ready to learn, rather than struggling to understand what the teacher is trying to teach and impart. Therefore, according to Currie, et al. [64] given the significance of cognitive and educational outcomes on wages, this is likely to be a key pathway that links nutrition to later economic wellbeing. 
In actual fact, nutrition's relationships with cognitive and educational development may be the most important pathway in terms of its impacts on wages. Save the Child [59] reported that the economic impacts of malnutrition are larger for those working in more skilled jobs than for those in manual jobs. Baird, et al. [65] showed that among those working for wages or operating small businesses as adults, those who had received an intervention to improve nutrition as children worked on average five extra hours per week, and earned 20\% more than those who didn't. These impacts were much larger than increases seen for farm workers. Hence, nutrition is not only significant for increasing economic outcomes of individuals; it is important for nations' economic development. Malnutrition also affects national economies by increasing healthcare costs, as people who were malnourished as children are more likely to fall ill to diseases Currie, et al. [64-78].

\section{Conclusion}

Diet is the number one risk factor for disease in the world; carrying a superior risk of ill health than smoking or drinking alcohol. According to the World Health Organization, 462 million adults are underweight, while 1.9 billion adults are overweight and obese. In children under 5 years of age, 155 million are stunted, 52 million are wasted, 17 million are severely wasted and 41 million are obese. Globally, there is hunger and malnutrition ravaging the world with a current estimated value of 1 in 9 people out of the 820 million people who are hungry or undernourished. Thus, the study found that presently Nigeria is one of the African countries listed among the 20 countries responsible for $80 \%$ of global malnutrition. The finding of the study also revealed that over the years, two main types of malnutrition have been identified in Nigerian children: protein-energy malnutrition and micronutrient malnutrition. The study discovered that the causes of malnutrition and food insecurity in Nigeria are multidimensional and include very poor infant and young child breastfeeding or feeding practices, which contribute to high rates of illness and poor nutrition among children under 2 years. The study discovered that young children with protein energy malnutrition suffer from brain atrophy; a shrinking of brain cells due to a lack of nutrients. The findings of the study revealed that stunted children earn as much as $20 \%$ less than their counterparts, and that today's malnutrition could potentially cost the global economy $\$ 125$ billion. The study concludes that nutrition is not only significant for increasing economic outcomes of individuals; it is important for nations' economic development, especially for a developing country like Nigeria.

\section{Recommendations}

Based on the findings, the following recommendations are put forward:
1. Since the study discovered that Nigeria is one of the African countries listed among the 20 countries responsible for $80 \%$ global malnutrition, the study recommends that the National Health and Nutrition Survey (HANS), and the Federal Ministry of Health should liaise to produce foods that are rich in nutritive contents.

2. The study recommends that breast feeding mothers should be educated on the significance of proper child breast feeding. This will boost the immune system of the children and reduce illness.

The Federal Government of Nigeria (FGN) should invest in nutrition programmes that will reduce protein energy malnutrition in order to control the rate at, which children suffer from brain astrophy.

\section{References}

1. Mills KT, Bundy JD, Kelly TN, Reed JE, Kearney PM, et al. (2016) Global disparities of hypertension prevalence and control: a systematic analysis of population based studies from 90 countries. Lippincott Williams \& Wilkins 134(6): 441-450.

2. (2019) World Health Organization (WHO) Malnutrition.

3. (2015) United Nations. The United Nations adopted the Sustainable Development Goals (SDGs)- a set of 17 global goals with specific targets aimed at ending poverty, protecting the planet and ensuring prosperity for all by 2030 .

4. (2019) FAO. The state of food security and nutrition in the world.

5. (2019) Food Security Information Network. Global report on food crisis.

6. Ng M, Fleming T, Robinson M, Thompson B, Graetz N, et al. (2014) Global, regional, and national prevalence of overweight and obesity in children and adults during 1980-2013: a systematic analysis for the Global Burden of Disease Study 2013. The Lancet 384(9945): 766-781.

7. (2018) OECD. States of fragility.

8. (2016) IFPRI. International Food Policy Research Institute (IFPRI): Global Food Policy Report, p. 154.

9. (2017) FAO, IFAD, UNICEF, WFP, WHO. The State of Food Security and Nutrition in the World: Building resilience for peace and food security. Rome, FAO, Italy.

10. Black MM (2008) Effects of vitamin B12 and folate deficiency on brain development in children. Food Nutrition Bulletin 29(2): S126-S131.

11.(2019) FAO, IFAD, UNICEF, WFP, WHO. The state of food security and nutrition in the world 2019. Safeguarding against economic slowdowns and downturns. Rome, FAO. Safeguarding against economic slowdowns and downturns. Rome, FAO.

12. (2017) OECD. Obesity updates, pp. 1-16.

13. Hughes L (2016) More spent on treating obesity-related conditions than on the police or fire service, says NHS Chief. The Telegraph.

14. Dobbs R, Manyika J, Woetzel J (2014) Overcoming obesity: An initial economic analysis. McKinsey Global Institute (November), p.120.

15. Black RE, Allen LH, Bhutta ZA (2008) Maternal and child under nutrition: global and regional exposures and health consequences. Lancet 371(9608): 243-260. 
16. (2013) Food and Agriculture Organization of the United Nations (FAO), IFAD, WFP. The state of food insecurity in the world 2013. The multiple dimensions of food security. Rome: FAO, Italy.

17. (2005) World Food Programme. Food and nutrition handbook. Rome, Italy.

18. (2014) International Food Policy Research Institute. Global Nutrition Report 2014: actions and accountability to accelerate the world's progress on nutrition. Washington, DC, USA.

19. Black RE, Victoria CG, Walker S, Bhutta Z, De Onis M, et al. (2015) UNICEF estimates.

20. (2017) NCD risk factor collaboration. Worldwide trends in body mass index, underweight, overweight, and obesity from 1975 to 2016: a pooled analysis of 2416 population based measurement studies in 128.9 million children, adolescents, and adults. The Lancet 390(10113): 2627 2642.

21. (2018) Global Nutrition Report.

22. Hancock C, Bettio S, Smith L (2016) Socioeconomic variation in height: analysis of National Child Measurement Programme data for England. Archives of Disease in Childhood 101(5): 422-426.

23. (2016) Lifestyle statistics team. National child measurement programme: England, 2015/16 school year. Health and Social Care Information Centre, (November), pp. 1-51.

24. (2017) Royal College of Paediatricians and Child Health. Poverty and child health Views from the frontline poverty and children's health: views from the frontline.

25. (2000) United Nations Administrative Committee on Coordination/ Sub-Committee on Nutrition (ACC/SCN). Fourth report on the world nutrition situation: nutrition throughout the life cycle. ACC/SCN in collaboration with IFPRI. Geneva.

26. (2016) Save the Children. Scaling up nutrition interventions for children left behind in Nigeria.

27. (2003) Nigeria Demographic and Health Survey (NDHS). Calverton, Maryland: National Population Commission and ORC Macro.

28. Maziya-Dixon B, Akinyele IO, Oguntona EB, Nokoe S, Sanusi RA, et al (2004) Nigerian Food Consumption and Nutrition Survey 2001-2003, summary. International Institute of Tropical Agriculture (IITA), Ibadan, Nigeria.

29. (2011) Multiple Indicators Clusters Survey (MICS). Multiple Indicators Clusters Survey. Monitoring the situation of children and women. UNICEF/NBS/UNFPA.

30. (2013) Nigeria Demographic and Health Survey (NDHS) (2013). Nigeria Demographic and Health Survey.

31. (2017) UNICEF. Iodine deficiency:a continuing threat to development How seven countries in eastern and southern Africa are meeting this threat. Nairobi: UNICEF, ESARO, p. 1-20.

32. Bhutta Z (2016) Early nutrition and adult outcomes: pieces of the puzzle. The Lancet 382(9891): 486-487

33. Rollins N, Bhandari N, Hajeebhoy N, Horton S, Lutter CK, et al. (2016) Why invest, and what will it take to improve breastfeeding practices? The Lancet 387(10017): 491-504.

34. Victoria CG, Bahl R, Barros AJD, Franca GVA, Horton S, et al. (2016) Breastfeeding in the $21^{\text {st }}$ century: epidemiology, mechanisms, and lifelong effect. The Lancet 387(10017): 475-490.

35. Shrimpton R, Victora CG, De Onis M, Lima RC, Blossner M, et al. (2001) Worldwide timing of growth faltering: implications for nutritional interventions. Paediatrics 107(5): 75-81.
36. Blössner M, DeOnis M (2005) Malnutrition: quantifying the health impact at national and local levels. In: environmental burden of disease series [Internet], p. 12.

37. Nutrition and South Africa's Children (n.d.).

38. Benson T (2008) Improving nutrition as a development priority: addressing undernutrition in national policy processes in sub-saharan Africa [Internet]. Washington DC: International Food Policy Research Institute.

39. Walton E, Allen S (2011) Malnutrition in developing countries. Paediatrics and Child Health 21(9): 418-424.

40. (2017) UNICEF. The state of the world's children.

41. (2014) Nigeria Federal Ministry of Health, Family Health Department. Health sector component of national food and nutrition policy: national strategic plan of action for nutrition. Abuja, Nigeria: Federal Ministry of Health.

42. Sachs J, Schmidt-Traub G, Kroll C, Durand-Delacre D, Teksoz K (2017) SDG index and dashboards report. New York: Bertelsmann stiftung and sustainable development solutions network (SDSN).

43. (2014) National Population Commission (NPC) [Nigeria] and ICF International. Nigeria Demographic and Health Survey 2013. Abuja, Nigeria, and Rockville, Maryland, USA: NPC and ICF International.

44. (2017) World Bank. Nigeria country overview.

45. Kippax S, Crawford J (1993) Flaws in the theory of reasoned action in the theory of reasoned action: its application to AIDS preventive behavior. In: Terry DJ, Gallois C, McCamish MM (Eds.)., Pergamon, New York, pp. 253-269.

46. Hardeman W, Johnston M, Johnston D, Bonetti D, Wareham N, et al. (2002) Application of the theory of planned behavior in behavior change interventions: a systematic review. Psychology \& Health 17: 123-158.

47. (2017) FEWSNET. Nigeria food security outlook, june 2017 to january 2018: populations in the northeast remain highly dependent on humanitarian assistance. Famine early warning systems network.

48. (2017) USAID. Food assistance fact sheet: Nigeria.

49. Fuglestad A, Rao R, Georgieff MK (2008) The role of nutrition in cognitive development. In: Nelson CA, Luciana M (Eds.)., Handbook in Developmental Cognitive Neuroscience, Cambridge, MA: MIT Press; 1999, pp. 491-50.

50. Jukes MCH, Drake LJ, Bundy DAP (2008) School health, nutrition and education for all: leveling the playing field. Wallingford: CAB international.

51. Allen LH (2000) Anemia and iron deficiency: effects on pregnancy outcome. American Journal of Clinical Nutrition 71(5): 1280S-1284S.

52. Prado E, Dewey K (2012) Insight nutrition and brain development in early life. AT\&T Technical Brief, 4.

53. Grantham-McGregor S, Ani C (2001) A review of studies on the effect of iron deficiency on cognitive development in children. Journal of Nutrition 131(2): 649S-668S.

54. (2001) World Health Organization. Iron deficiency anaemia: assessment, prevention, and control - a guide for programme managers, Geneva: WHO

55. Goonewardene M, Shehata M, Hamad A (2012) Anaemia in pregnancy. Best Practice \& Research Clinical Obstetetrics \& Gynaecology 26(1): 3-24.

56. (2008) WHO cited in The Lancet. 'Iodine deficiency - way to go yet'. The Lancet 372: 9633 
57. Morgane P, Mokler D, Galler JR (2002) Effect of parental protein malnutrition on the hippocampal formation. Neurosci Biobehav 26(4): 471-83.

58. (2011) Duke University Medical Center. 'Zinc regulates communication between brain cells'. Science Daily.

59. Hamadani JD, Fuchs GJ, Osendarp SJM, Huda SN, Grantham McGregor SM (2002) Zinc supplementation during pregnancy and effects on mental development and behaviour of infants: a follow-up study'. The Lancet 360: 290-294

60. (2013) Save the child. Food for thought: tackling child malnutrition to unlock potential and boost prosperity. London: Save the Child.

61. Victoria CG, Adair L, Fall C, Hallal PC, Martorell R, et al. (2008) Maternal and child undernutrition: consequences for adult health and human capital. maternal and child undernutrition 371(9609): P340-357.

62. Hoddinott J, Maluccio J, Behrman JR, Martorell R, Melgar P, et al. (2011) The consequences of early childhood growth failure over the life course. IFPRI Discussion Paper 01073

63. Hanushek EA, Woessmann L (2009) Do better schools lead to more growth? Cognitive skills, economic outcomes, and causation. NBER working paper no. 14633 .

64. Currie J, Vogl T (2012) Early life health and adult circumstance in developing countries. Princeton.

65. Baird S, Hicks JH, Kremer M, Miguel E (2011) Worms at work: long run impacts of child health gains.

66. Black MM (2003) The evidence linking zinc deficiency with children's cognitive and motor functioning. Journal of Nutrition 133: 1473S-1476S.

67. El Sherif AM, Babrs GM, Ismail AM (2012) Cranial magnetic resonance imaging (MRI) changes in severely malnourished children before and after treatment. Life Science Journal 9(3): 589-592

\section{ISSN: 2574-1241}

DOI: $10.26717 /$ BJSTR.2021.39.006237

Aondover Eric Msughter. Biomed J Sci \& Tech Res

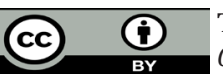

This work is licensed under Creative Commons Attribution 4.0 License

Submission Link: https://biomedres.us/submit-manuscript.php
68. (2004) Federal Ministry of Health (FMOH)/M.I/UNICEF. Vitamin and mineral deficiency damage assessment report Nigeria.

69. Francis B, Iyare S (2006) Education and development in the Caribbean: a cointegration and causality approach. Economics Bulletin 15 (2): 1-13.

70. Hoddinott J, Rosegrant M, Torero M (2012) Copenhagen consensus challenge paper: Hunger and Malnutrition.

71. Joel AB, Amuwaoluwa OE, Abdu H, Olosunde O, Lasisi K (2018) Evaluation of nutritional status of under- 5 children in Borno and Kano States of Nigeria. Ife Social Sciences Review 26(1): 66-73.

72. Murphy L (2013) Nutritional status in northern Nigeria, prevalence and determinants: a review of evidence.

73. (1990) Nigeria Demographic and Health Survey (NDHS). Columbia, Maryland: FOS and IRD.

74. Ranade SC (2008) Different types of nutritional deficiencies affect different domains of spatial memory function checked in a radial arm maze. Neuroscience 152(4): 859-866.

75. Saiful IT, Wadud MA, Islam BT (2007) Relationship between education and GDP growth: a mutivariate causality analysis for Bangladesh. Economics Bulletin 35 (3): 1-7.

76. Sandys L (2017) MPs need to stop food becoming a political hot potato | News | The Times \&The Sunday Times. The Times.

77. (2012) Save the Children A life free from hunger: tackling child malnutrition, london: save the children.

78. (1992) UNICEF. National Strategies for Overcoming Micronutrient Malnutrition: Nutrition Paper of the Month. New York.

$\begin{array}{ll}\text { BIOMEDICAL } & \text { Assets of Publishing with us } \\ \text { RESEARCHES } & \text { - Global archiving of articles } \\ \text { - Immediate, unrestricted online access }\end{array}$

